\title{
Reach and Operating Time Correction of Digital Distance Relay
}

\author{
A. N. Sarwade ${ }^{1}$, P. K. Katti ${ }^{2}$, J. G. Ghodekar ${ }^{3}$ \\ ${ }^{1,2}$ Departement of Electrical Engineering, Dr Babasaheb Ambedkar Technological University, Lonere, India \\ ${ }^{3}$ Retired Principal, Govt College of Engineering, Shivaji University, India
}

\begin{tabular}{l}
\hline \hline Article Info \\
\hline Article history: \\
Received Oct 14, 2016 \\
Revised Nov 15, 2016 \\
Accepted Dec 8, 2016
\end{tabular}

Keyword:

CT saturation

Distance relay

PSCAD-EMTDC

Rogowski coil

Under reach

\begin{abstract}
Current and voltage signals recieved from conventional iron core Current Transformer (CT) and Voltage Transformer plays very important role for correct operation of Distance Distance Relay (DDR). Increase in secondary burden connected to CT causes it to saturate at earlier stage. The saturated CT produces distorted secondary current, causing DDR to under reach and to operate by certain time delay. Rogowski Coils (RCs) are attaining increased acceptance and use in electrical power system due to their inherent linearity, greater accuracy and wide operating current range. This paper presents use of $\mathrm{RC}$ as an advanced measurement device suitable for DDR. Case study for validation of use of RC is carried out on low voltage system. The simulation results of Distance protection scheme used for protection of part of $220 \mathrm{kV}$ AC system shows excellent performance of RC over CT under abnormal conditions.
\end{abstract}

Copyright $\odot 2017$ Institute of Advanced Engineering and Science. All rights reserved.

\section{Corresponding Author:}

\section{A. N. Sarwade,}

Research Scholar, Departement of Electrical Engineering,

Dr. Babasaheb Ambedkar Technological University,

Lonere, Raigarh, Maharashtra, India.

Email: asarwade@yahoo.com

\section{INTRODUCTION}

Power system is a complex interconnected network which consists of generation, transmission and distribution utilities. Short circuit and other eccentric conditions which occur in the power system called faults [1]. According to statistical data about 70 to $80 \%$ faults on transmission line are single line to ground faults [2]. The performance distance relays (DRs) used for protection of transmission line when a fault occurs in the system is important for improvements in the stability of the system and reduction of their effect on sensitive loads. Reducing the fault clearing time for more possible fault conditions is one of the main goals in the development, application and setting of such relays [3].

Fault occurred on transmission line produce very large and abnormal currents in the power system. Traditionally normal and abnormal current measurement is accomplished with magnetic core Current Transformer (CT). CT produces reduced current accurately proportional to current which can be conveniently connected to measuring and recording instruments. But CT exposes a series of defects such as complex insulating structure, saturation potential and catastrophic failure due to secondary open [4].

CT saturation cause distance relay to see lower effective current than they would see and causes them to reach a shorter distance than they would, if there were no CT saturation. This also causes the distance protection scheme to provide its trip decision with certain time delay [5]. To overcome this issue, a new measuring technique is required for measurement of current.

In order to use microprocessor-based or numerical relays, more advanced instrument current transducers must be introduced for measurements [6-8]. Rogowski Coil (RC) has attracted much attention of electric power industry as it can meet the requirements of protective relaying due to its superior performance, inherent linearity, outstanding dynamic response, wide bandwidth and no magnetic saturation. The position of the primary conductor inside RC, magnetic field created by nearby conductors and harmonics will not create 
any type of deviation in RC output [9], [10]. High degree of selectivity and characteristics of protections which require current measurements can be increased significantly in the protection system with the help of $\mathrm{RC}$. So, RC can be considered as alternative to conventional current transformers for applications in harsh operation environments [11].

So far RC is used as current transducer in differential and over current protection. This paper presents use of RC as a best alternative to conventional CT in $220 \mathrm{kV}$ distance protection scheme.

\section{RESEARCH METHOD}

This paper gives the comparision of the performance of $220 \mathrm{kV}$ distance protection scheme when CT and $\mathrm{RC}$ are used as current transducers. The stages involved while developing a distance protection scheme are shown in Figure 1. The fault created on an AC system produces current and voltage signals with some transients. The voltage signal is collected with the help VT and the current signal is collected with the help of RC, ideal CT and actual CT simultaneously. In order to get correct value of the line impedance up to fault point, it is very essential to remove the transients and retain signals with fundamental frequency. So these signals are further processed through signal processing stage which carries FFT module. FFT module helps to obtain current and voltage signals at fundamental frequency [12]. By using these current and voltage signals, apparent impedances $\left(Z_{a p} s\right)$ are calculated. Finally these $Z_{a p} s$ are fed to MDRs which compares these impedances with its setting and issues trip signal instantaneously or with some time delay.

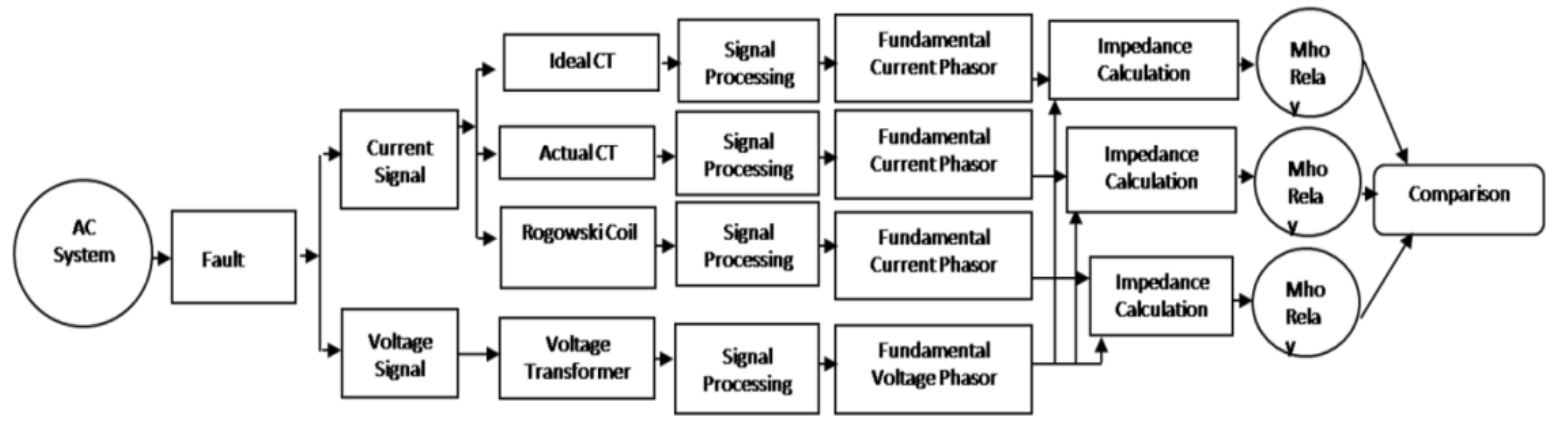

Figure 1. Distance Protection Scheme Stages

\subsection{Modelling of $220 \mathrm{kV}$ AC System}

The details of the $220 \mathrm{kV}$ AC system (Figure 2) is given in Table 1. Line between bus A and bus B is protected by using MDR. The line AB is divided in two parts as TLine1 and TLine2 to obtain its Zone 1 setting (Z1set). The line lengths of these two parts can be varied to create a fault inside and outside of Zone 1 of line AB. Single line to ground (SLG) fault is created with the help of time fault logic [13].

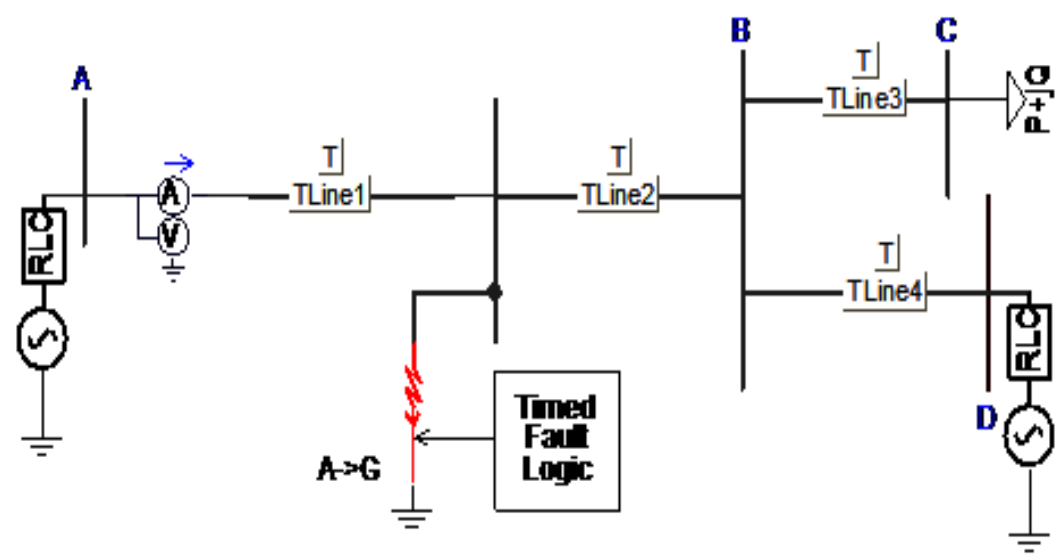

Figure 2. PSCAD model of 220kV AC System 
Table 1. $220 \mathrm{kV}$ AC System Details

\begin{tabular}{|c|c|}
\hline Parameter & Specifications \\
\hline Source Voltage & $220 \mathrm{kV}, 50 \mathrm{~Hz}$ \\
\hline Source Impedance & $32.15 \angle 85^{\circ} \Omega$ \\
\hline System MVA & 100 MVA \\
\hline Length of $\mathrm{AB}$ & $200 \mathrm{~km}$ \\
\hline Positive sequence impedance(per km) & $0.2928 \angle 86.57^{0} \Omega$ \\
\hline Zero sequence Impedance (per km) & $1.11 \angle 74.09^{0} \Omega$ \\
\hline Load & $(75+\mathrm{j} 25) \mathrm{MVA}$ \\
\hline compensation factor & 2.82 \\
\hline
\end{tabular}

\subsection{Modeling of Actual Current Transformer}

The actual CT with the following specifications is used (Figure $3 \&$ Table 2) [14].

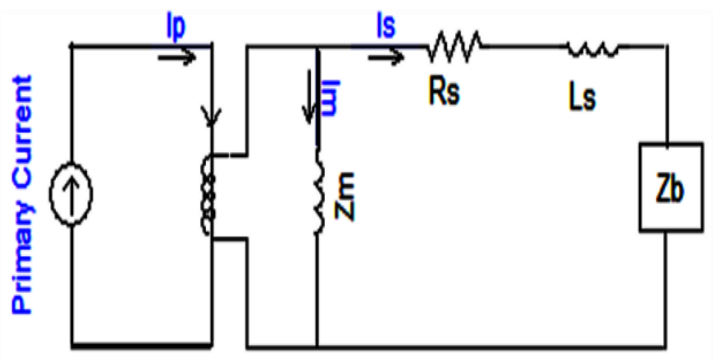

Figure 3. Actual CT Model

Table 2. CT Details

\begin{tabular}{lc}
\hline \multicolumn{1}{c}{ Parameter } & Specifications \\
\hline CT ratio (CTR) & $270 / 1$ \\
Secondary winding Resistance (Rs) & $0.5 \Omega$ \\
Secondary winding Inductance (Ls) & $0.8 \mathrm{mH}$ \\
Magnetic Core Area & $2.6 \times 10-3 \mathrm{~mm} 2$ \\
Magnetic Path Length & $0.677 \mathrm{mtr}$ \\
CT Burden (Zb) & $(0.5+\mathrm{j} 0.251) \Omega$ \\
\hline
\end{tabular}

\subsection{Modelling of Ideal Current Transformer}

The primary current is divided by number of turns which have been considered in actual current transformer, to get ideal value of secondary current (Figure 4).

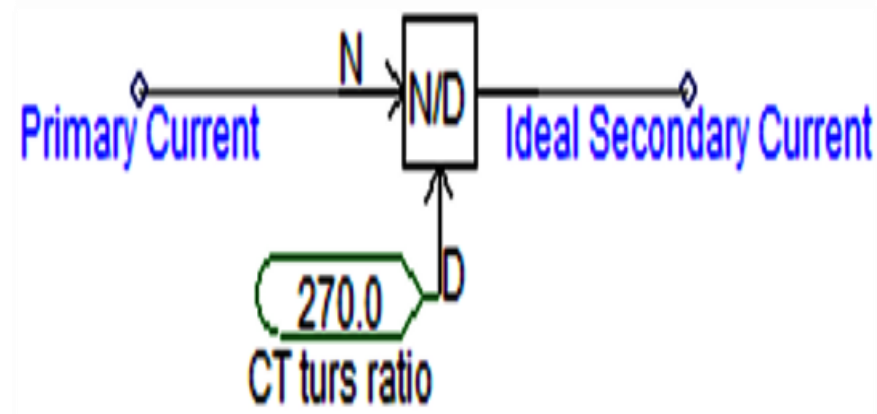

Figure 4. Ideal CT Model

\subsection{Modelling of Rogowski Coil}

The RC module \& integrator with the following specifications is used (Figure 5 \& Table 3) [15-16]. 


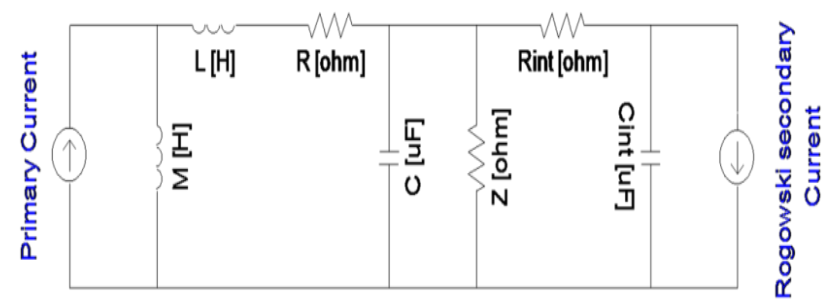

Figure 5. Rogowski Coil Model

Table 3. Rogowski Coil Details

\begin{tabular}{lclc}
\hline \multicolumn{1}{c}{ Parameter } & Specifications & \multicolumn{1}{c}{ Parameter } & Specifications \\
\hline Mutual Inductance & $2 \mu \mathrm{H}$ & R of Integrator(Rint) & $100 \Omega$ \\
L of Rogowski Coil & $7.8 \mathrm{mH}$ & C of Integrator(Cint) & $1 \mu \mathrm{F}$ \\
R of Rogowski Coil & $186 \Omega$ & No of turns & 270 \\
C of Rogowski Coil & $235 \mathrm{pF}$ & Output RMS & $100 \mathrm{mV} / 1 \mathrm{kA}$ \\
Z of Rogowski Coil & $2 \mathrm{k} \Omega$ & Rated Current & $100 \mathrm{kA}$ \\
\hline
\end{tabular}

\section{RESULTS AND ANALYSIS}

Zone-1 setting (Z1set) of MDR used for protection of line $\mathrm{AB}$ (Figure 2) is given by Equation 1 [17].

$$
Z_{1 \text { set }}=80 \% \text { of Impedance of protected line } A B \text { on secondary side }
$$

Using Equation 1, Z1 set of MDR for $200 \mathrm{~km}$ line is done at $160 \mathrm{~km}(80 \%$ of $200 \mathrm{~km})$. To observe the under reach phenomenon of the MDR, line length of TLine1 is adjusted as $150 \mathrm{~km}$ (Figure 2). The burden connected to CT secondary is increased to obtain CT saturation condition. Use of ideal CT, actual CT and RC in distance protection scheme is analyzed with the help of secondary current waveforms, B-H curves, Zap trajectories and operating time of MDR.

\subsection{Impact of CT Secondary Burden}

To observe the effect of unsaturated and saturated CT, the burden connected to its secondary is varied from $0.5 \Omega$ to $10 \Omega$.

\subsubsection{Transient Response}

Figure 6a to 6e shows the secondary current waveforms generated by use of Ideal CT (blue), Actual $\mathrm{CT}$ (red) and RC (green). When the fault is created at maximum value of voltage (Vmax), with relay burden $(\mathrm{Rb})$ of $0.5 \Omega$, it is observed that ideal $\mathrm{CT}$, actual $\mathrm{CT}$ and RC produces symmetrical secondary current waveforms which are overlaying on each other (Figure 6(a)). With the same burden Rb, when the fault is created at zero voltage, the current waveforms found to be shifted upwards from the reference due to DC offset and some distortions are observed in secondary current waveforms produced by actual CT (Figure 6(b)). When Rb is increased to $2 \Omega, 5 \Omega$ and $10 \Omega$, it is observed that the actual CT secondary waveform obtains more and more clipped and distorted shape (Figure 6(c) - 6(e)), whereas it is found that RC transforms primary current faithfully on secondary side as its secondary current waveform overlaying on secondary current waveform produced by ideal CT.

Comparison of the secondary current root means square (rms) values at different burdens are given by Table 4 . It is observed that rms value of the secondary current produced by ideal CT and RC are approximately equal, but in case of actual $\mathrm{CT}$ it goes on reducing with increase in burden.

Table 4. Secondary Currents at different CT Burdens

\begin{tabular}{cccccc}
\hline Instant of Fault & $\mathrm{v}=\mathrm{Vmax}$ & \multicolumn{5}{c}{ Secondary Burden } \\
Relay Burden $(\mathrm{Rb})$ & $0.5 \Omega$ & $0.5 \Omega$ & $2 \Omega$ & $5 \Omega$ & $10 \Omega$ \\
\hline Without CT (A) & 4.21 & 4.25 & 4.25 & 4.25 & 4.25 \\
With CT (A) & 4.21 & 3.72 & 3.52 & 3.35 & 3.205 \\
With Rogowski Coil (A) & 4.22 & 4.26 & 4.26 & 4.26 & 4.26 \\
\hline
\end{tabular}



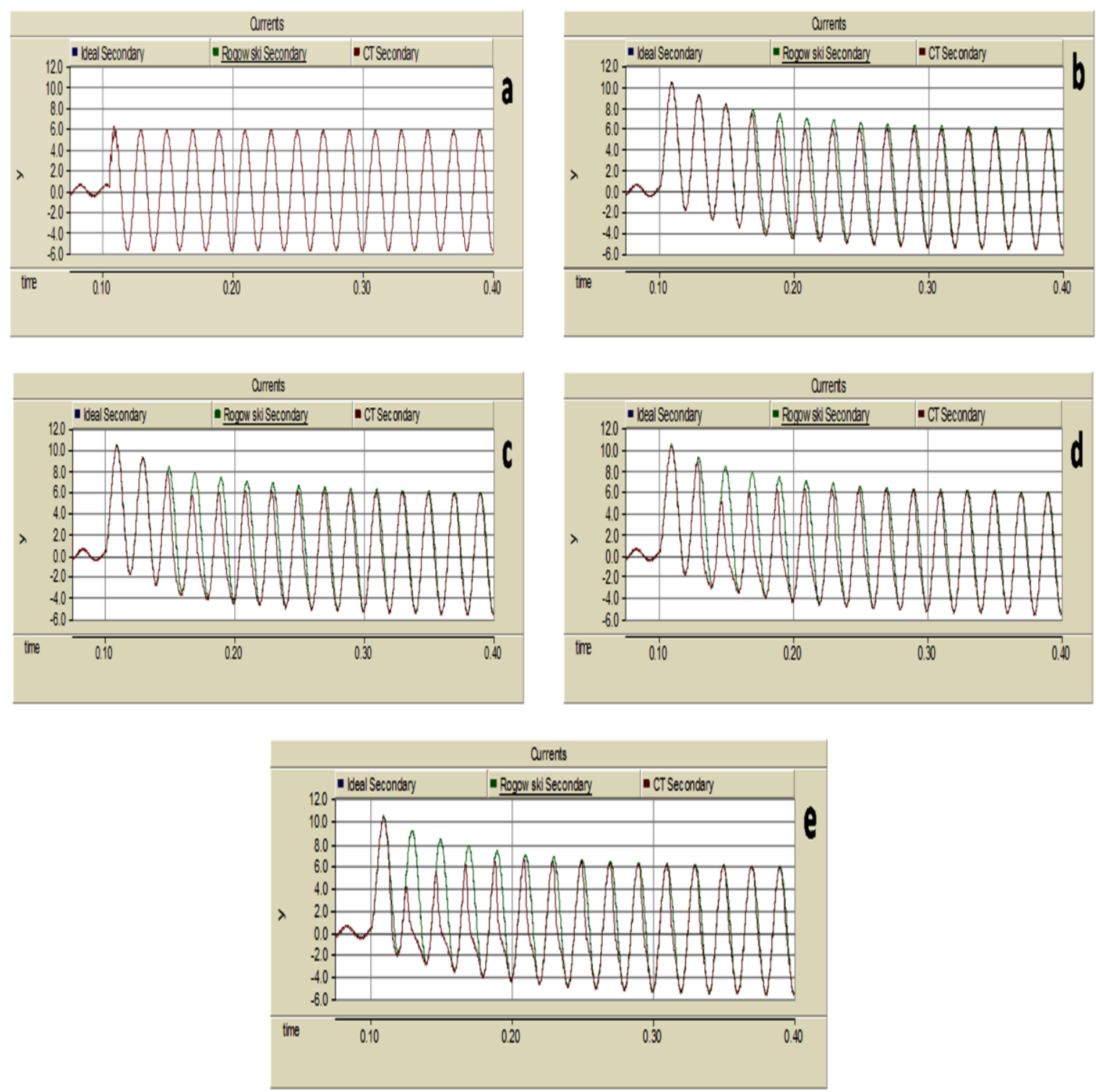

Figure 6. Secondary Current Waveforms (a) $\mathrm{Rb}=0.5 \Omega$ \& Fault at $\mathrm{v}=\mathrm{Vmax}$, (b) $\mathrm{Rb}=0.5 \Omega \&$ Fault at $\mathrm{v}=0$, (c) $\mathrm{Rb}=2 \Omega \&$ Fault at $\mathrm{v}=0$, (d) $\mathrm{Rb}=5 \Omega \&$ Fault at $\mathrm{v}=0$, (e) $\mathrm{Rb}=10 \Omega$ \& Fault at $\mathrm{v}=0$

\subsubsection{B-H Curves of CT}

Figure 7(a)-7(e) shows, B-H curves generated by magnetization of actual CT. CT gives linear B-H curve (Figure 7(a)), when the fault is created at Vmax with CT burden as $0.5 \Omega$. With same CT burden, when the fault is created at $v=0, C T$ gets saturated (Figure 7(b)). CT goes in deep saturation when the burden is increased from $2 \Omega$ to $10 \Omega$ and it requires more magnetizing force to produce same amount of flux density (Figure 7(c)-7(e)).

After CT saturation, it is observed that, increase in CT burden increases magnetizing force required to produce same amount of flux density (Table 5).

Table 5. B \& H parameters at last saturation point with different burdens

\begin{tabular}{lccccc}
\hline \multicolumn{1}{c}{ Instant of Fault } & $\mathrm{v}=\mathrm{Vmax}$ & \multicolumn{4}{c}{$\mathrm{v}=0$} \\
\hline $\mathrm{Rb}($ Relay Burden $)$ & $0.5 \Omega$ & $0.5 \Omega$ & $2 \Omega$ & $5 \Omega$ & $10 \Omega$ \\
$\mathrm{B}\left(\mathrm{Wb} / \mathrm{m}^{2}\right)$ & 0.27 & 2 & 2 & 2 & 2 \\
$\mathrm{H}(\mathrm{AT} / \mathrm{m})$ & 7.75 & 1955 & 2597 & 3296 & 3840 \\
\hline
\end{tabular}




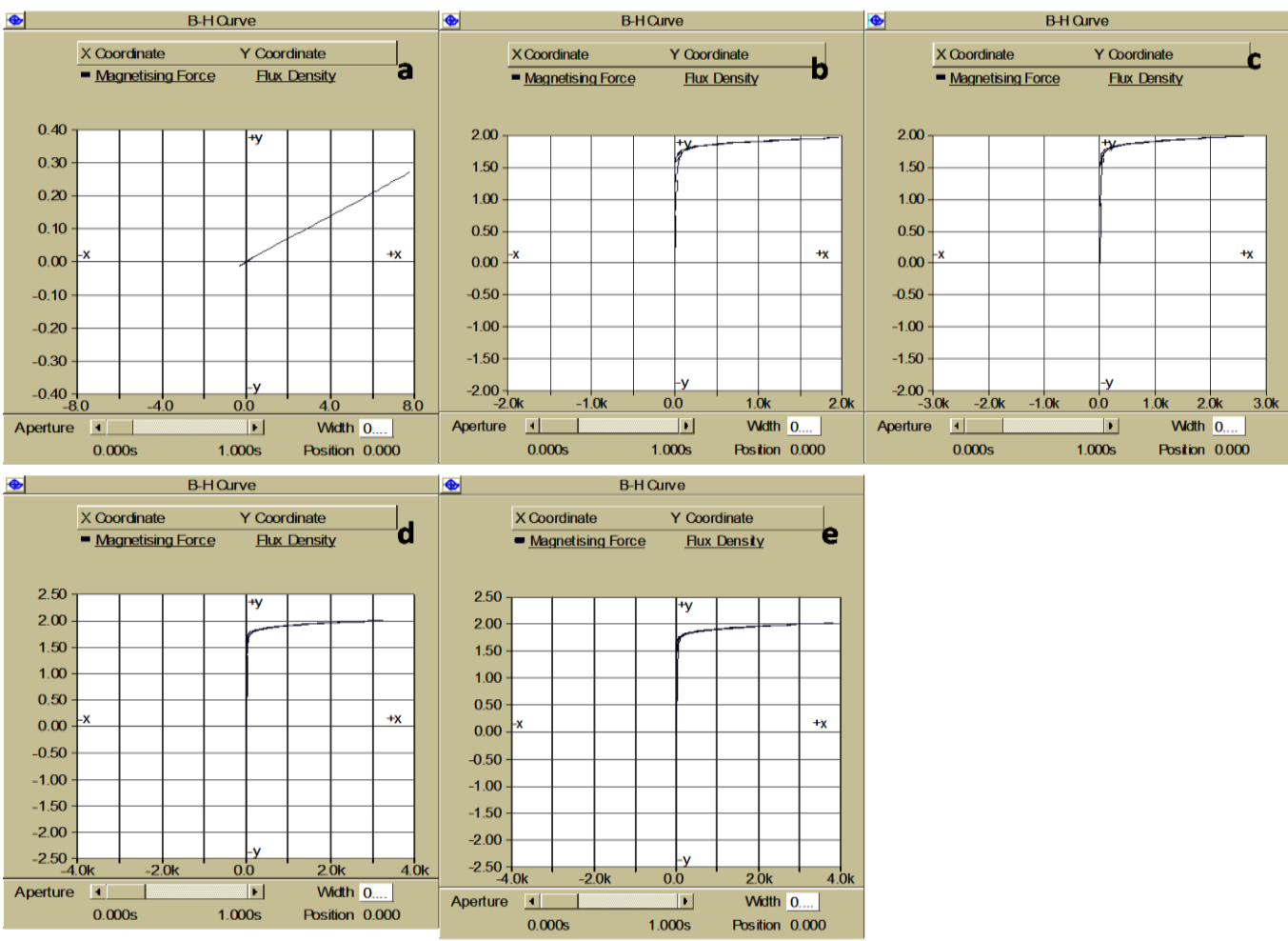

Figure 7. B-H Curves at different Burden, (a) $\mathrm{Rb}=0.5 \Omega \&$ fault at $\mathrm{v}=\mathrm{Vmax}$, (b) $\mathrm{Rb}=0.5 \Omega \&$ fault at $\mathrm{v}=0$, (c) $\mathrm{Rb}=2 \Omega \&$ fault at $\mathrm{v}=0$, (d) $\mathrm{Rb}=5 \Omega$ \& fault at $\mathrm{v}=0$, (e) $\mathrm{Rb}=10 \Omega \&$ fault at $\mathrm{v}=0$

\subsubsection{V-I Characteristics of Rogowski Coil (Case Study)}

Rogowski coil which was installed in Gujarat state for Electric Furnace purpose is shown in Figure 8 [18-19]. The results of the prototype installation for induction Furnace application are given in Table 6. The input output characteristics of Rogowski coil is shown in Figure 8. It is observed that the characteristics remain linear throughout the operating range of 0 Amp to $10 \mathrm{kA}$.
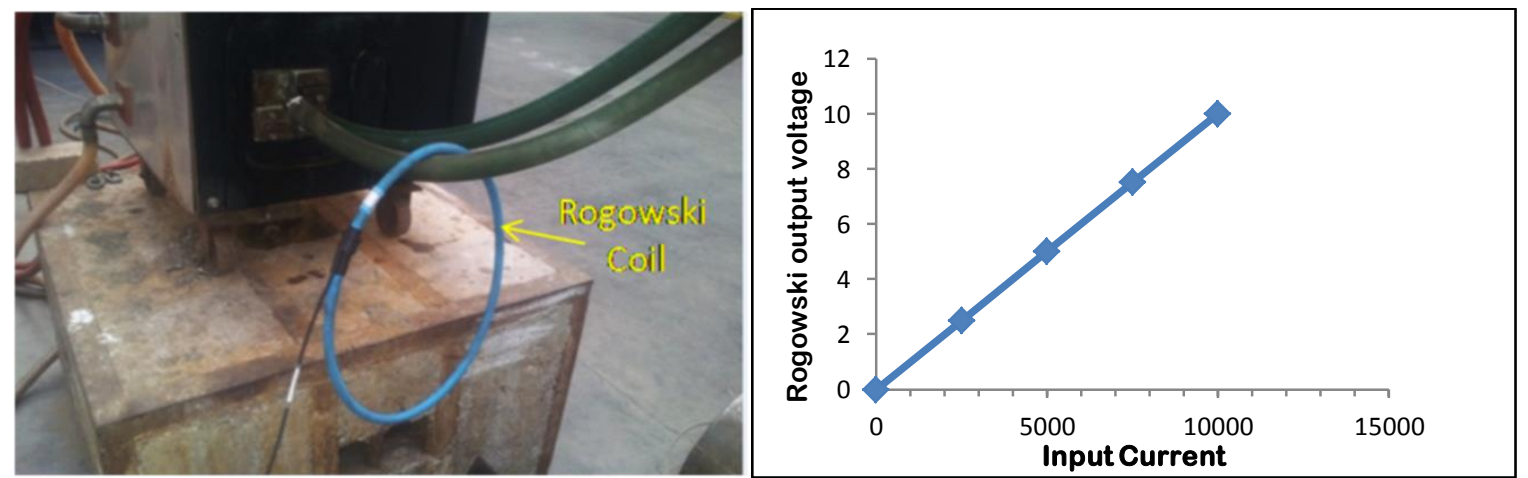

Figure 8. Installation of Rogowski Coil for Electric Furnance Application and its V-I Characteristics

Table 6. Parameters observed on Input and Output side of Rogowski Coil

\begin{tabular}{cccc}
\hline Sr. No. & Input Current & Rogowski output voltage & Output from Integrator \\
\hline 1 & $10 \mathrm{KA}$ & $10 \mathrm{~V}$ & $20 \mathrm{~mA}$ \\
2 & $7.5 \mathrm{KA}$ & $7.5 \mathrm{~V}$ & $16 \mathrm{~mA}$ \\
3 & $5 \mathrm{KA}$ & $5 \mathrm{~V}$ & $12 \mathrm{~mA}$ \\
4 & $2.5 \mathrm{KA}$ & $2.5 \mathrm{~V}$ & $8 \mathrm{~mA}$ \\
5 & $0 \mathrm{~A}$ & $0 \mathrm{~V}$ & $4 \mathrm{~mA}$ \\
\hline
\end{tabular}




\subsubsection{Apparent Impedance}

Figure 9a to Figure 9e shows Zap trajectories with ideal CT (green), actual CT (red) and RC (blue) along with Mho circle, when SLG fault is created at $150 \mathrm{~km}$. Before saturation of CT, it is observed that all the $Z_{a p}$ trajectories are overlaying on each other (Figure 9a). Figure 9b-9e shows that the $Z_{a p}$ trajectory (red) is significantly impacted by the CT saturation. To have a correct tripping of the relay, $Z_{a p}$ trajectory must fall inside Zone 1 . But when the CT gets saturated, $Z_{a p}$ trajectory lies outside of its Zone 1 boundary. As the CT comes out from saturation state, the impedance seen by MDR matches the unsaturated plot. Therefore, MDR shows to have a tendency to under reach.

Table 7 gives the values of Zap obtained with different fault instants and increased burdens. The clipping of secondary current due CT saturation increases the magnitude of impedance seen by Mho element. It is observed that with increase in burden, Zap increases.

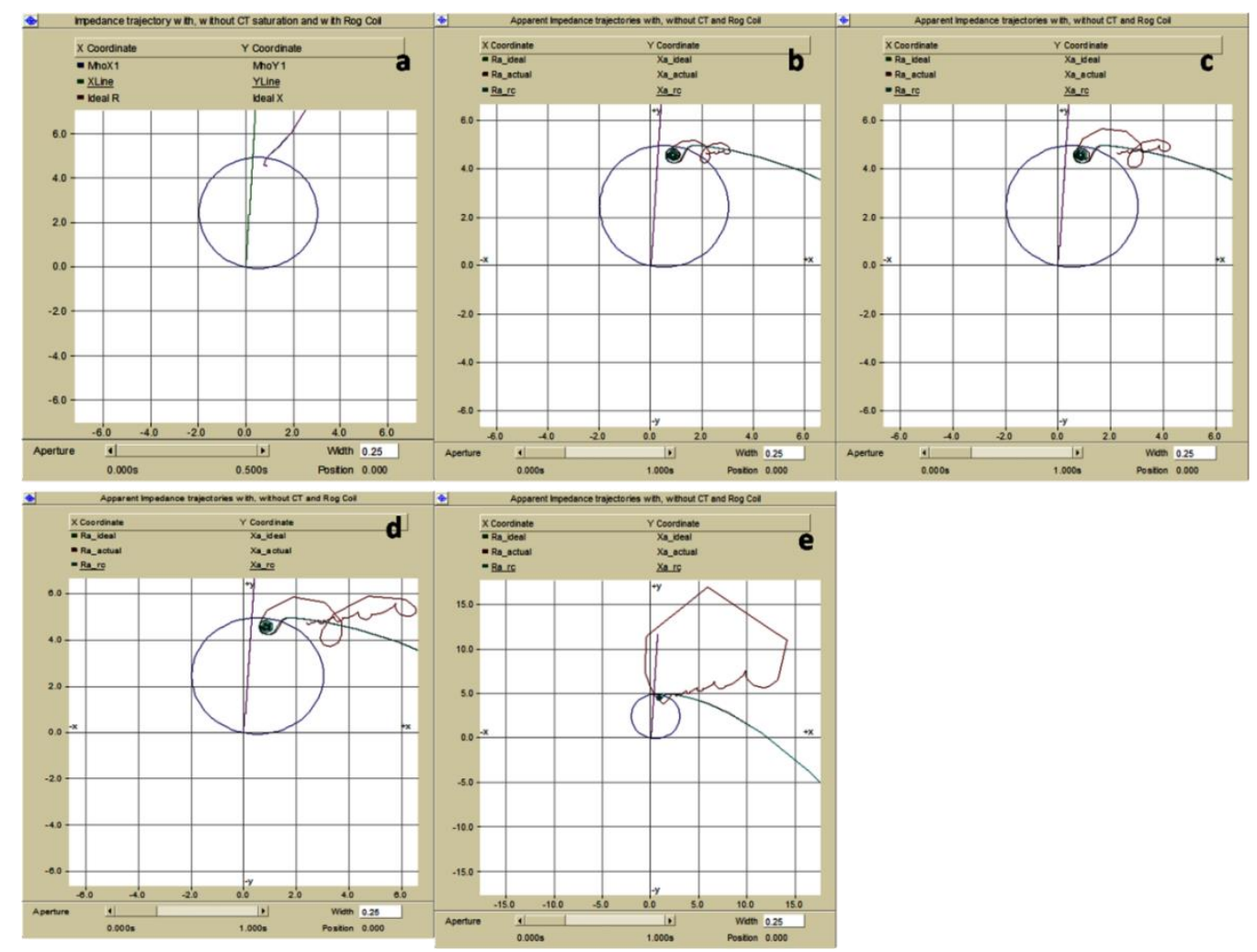

Figure 9. Impedance Trajectories on Mho Element with different Burdens (a) $\mathrm{Rb}=0.5 \Omega \&$ fault at $\mathrm{v}=\mathrm{Vmax}$, (b) $\mathrm{Rb}=0.5 \Omega$ \& fault at $\mathrm{v}=0$, (c) $\mathrm{Rb}=2 \Omega$ \& fault at $\mathrm{v}=0$, (d) $\mathrm{Rb}=5 \Omega$ \& fault at $\mathrm{v}=0$,

(e) $\mathrm{Rb}=10 \Omega \&$ fault at $\mathrm{v}=0$

Table 7. $Z_{a p}$ at different Burdens

\begin{tabular}{cccccc}
\hline Fault instant & $\mathrm{v}=\mathrm{Vmax}$ & \multicolumn{4}{c}{$\mathrm{v}=0$} \\
$\mathrm{Rb}$ & $0.5 \Omega$ & $0.5 \Omega$ & $2 \Omega$ & $5 \Omega$ & $10 \Omega$ \\
\hline Ideal CT & $4.63 \angle 79.21^{0}$ & $4.69 \angle 78.16^{0}$ & $4.69 \angle 78.16^{0}$ & $4.69 \angle 78.16^{0}$ & $4.69 \angle 78.16^{0}$ \\
With CT & $4.64 \angle 79.01^{0}$ & $5.06 \angle 65.61^{0}$ & $5.14 \angle 65.30^{0}$ & $5.24 \angle 63.84^{0}$ & $5.32 \angle 63.10^{0}$ \\
With RC & $4.62 \angle 79.34^{0}$ & $4.68 \angle 78.30^{0}$ & $4.68 \angle 78.30^{0}$ & $4.68 \angle 78.30^{0}$ & $4.68 \angle 78.30^{\circ}$ \\
\hline
\end{tabular}

\subsubsection{Operating time}

The operating time of a DR is considerable to make sure of high speed tripping. Before CT saturation, all Mho relay elements issues their tripping signals at same instant (Figure 10a). When CT burden is increased from $2 \Omega$ to $10 \Omega$, CT goes in deep saturation. This CT saturation process causes the Zap to lie outside of Zone1 for some time and to return back when CT comes out of saturation. It delays Mho relay element operation connected to actual CT and result in slower than expected tripping times (Figure 10b-10e). 
Table 8 gives the time required for the DR to operate, when the burden is increased from 0.5 to $10 \Omega$. It is observed that increase in CT burden, increases the magnitude of the $Z_{a p}$, causing delay in the time of operation.
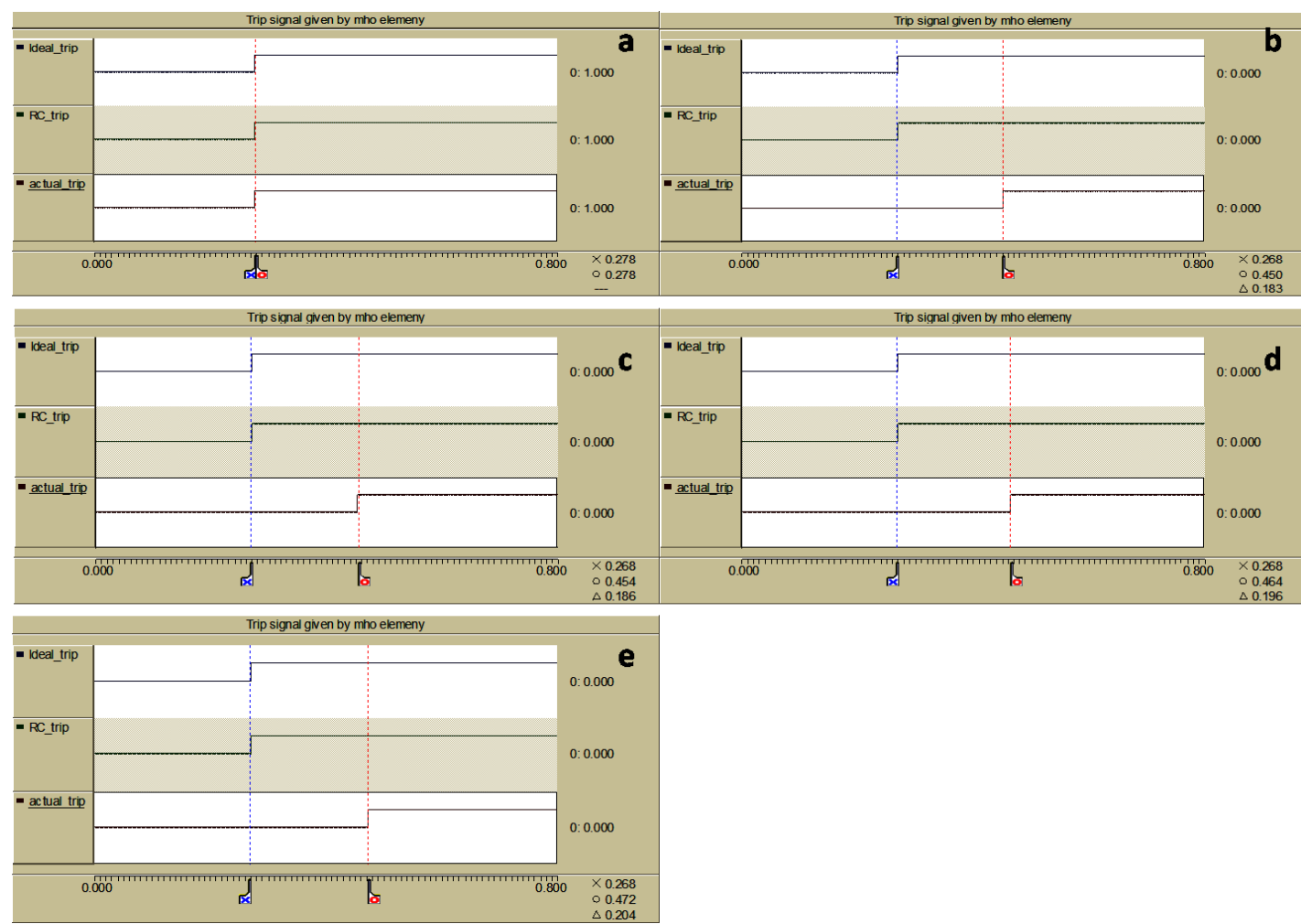

Figure 10. Tripping Signals with different Burdens (a) $R b=0.5 \Omega \&$ fault at $v=V m a x,(b) R b=0.5 \Omega \&$ fault at $\mathrm{v}=0$, (c) $\mathrm{Rb}=2 \Omega$ \& fault at $\mathrm{v}=0,(\mathrm{~d}) \mathrm{Rb}=5 \Omega$ \& fault at $\mathrm{v}=0$, (e) $\mathrm{Rb}=10 \Omega$ \& fault at $\mathrm{v}=0$

Table 8. Tripping Times at different Burdens

\begin{tabular}{|c|c|c|c|c|c|}
\hline Fault Instant & $\mathrm{v}=\mathrm{V} \max$ & \multicolumn{4}{|c|}{$\mathrm{v}=0$} \\
\hline Relay Burden & $0.5 \Omega$ & $0.5 \Omega$ & $2 \Omega$ & $5 \Omega$ & $10 \Omega$ \\
\hline Without CT & Instantaneous & Instantaneous & Instantaneous & Instantaneous & Instantaneous \\
\hline With CT & Instantaneous & After $0.183 \mathrm{~S}$ & After $0.186 \mathrm{~S}$ & After $0.196 \mathrm{~S}$ & After $0.204 \mathrm{~S}$ \\
\hline With RC & Instantaneous & Instantaneous & Instantaneous & Instantaneous & Instantaneous \\
\hline
\end{tabular}

\section{CONCLUSION}

Low voltage case study and conducted simulations on $220 \mathrm{kV}$ AC system show use and importance of RC in digital DPS. Influence of secondary burden of CT was investigated and it is proved that saturated CT produces a highly distorted secondary current. After changing the burden from $0.5 \Omega$ to $2.5 \Omega$ a small indication of core saturation was observed for at least 6 cycles after the fault. After setting burden to $10.0 \Omega$, distortions were present during the whole simulation and they caused RMS current to be smaller than in fact it was. This means that for a highly reactive fault path the current measured by a CT in the first few cycles is significantly smaller than the actual fault current. This can cause the Distance Relay to under reach and trip after a longer period of time than it was originally anticipated. Rogowski coil produces exact replication of primary current without distorting it with any load burden and prevent under reach phenomenon.

\section{REFERENCES}

[1] P. Sharma, et al., "Fault Detection and Classification in Transmission Line Using Wavelet Transform and ANN," Bulletin of Electrical Engineering and Informatics, vol/issue: 5(3), pp. 284-295, 2016. 
[2] N. Ghaffarzadeh, "A New Method for Recognition of Arcing Faults in Transmission Lines using Wavelet Transform and Correlation Coefficient," Indonesian Journal of Electrical Engineering and Informatics (IJEEI), vol/issue: 1(1), pp. 1-7, 2013.

[3] U. Klapper, et al., "Why we should measure line Impedance," Omicron Electronics, pp. 1-10

[4] Q. Huang, et al., "Innovative Testing and Measurement Solutions for Smart Grid," pp. 304, 2015.

[5] P. Sawko, "Impact of Secondary Burden and X/R Ratio on CT Saturation," Wroclaw University of Technology, Faculty of Electrical Engineering, pp. 1-3, 2008. [zet10.ipee.pwr.wroc.pl]

[6] Kojovic L., "Rogowski coils suit relay protection and measurement," IEEE Computer Applications in Power, vol/issue: 10(3), pp. 47-52, 1997.

[7] G. Weng and H. Jiang, "Measurement of medium and high-voltage system bus current based on Rogowski coil," Electrician Electr, pp. 2-43, 2009.

[8] Kojovic L. and Bishop M. T., "Field experience with differential protection of power transformers based on Rogowski coil current sensors," Actual trends in development of power system protection and automation 7-10 September 2009, Moscow, Russia, 2009.

[9] IEEE PSRC report, "Practical Aspects of Rogowski Coil Applications to Relaying," Power System Relaying Committee of the IEEE Power Engineering Society, pp. 1-72, 2010.

[10] V. Skendzic and B. Hughes, Schweitzer Engineering Laboratories, Inc. "Using Rogowski Coils Inside Protective Relays," 66th Annual Conference for Protective Relay Engineers College Station, Texas, 8th -11th April 2013, 2013.

[11] D. B. Solovev and A. S. Shadrin, "Instrument current transducers with Rogowski coils in protective relaying applications," Electrical Power and Energy Systems, vol. 73, pp. 107-113, 2015.

[12] A. N. Sarwade, et al., "Optimum Setting of Distance Protection Scheme for HV Transmission Line," Journal of Power Electronics and Power Systems, STM, vol/issue: 3(2), pp. 23-30, 2013.

[13] Power System simulation software, "PSCAD/EMTDC 4.2.1," Manitoba HVDC Research Centre Inc., Canada, 2008.

[14] D. Muthumuni, et al., "Modelling Current Transformer saturation for detailed Protection studies," Pulse Newletter, Manitoba HVDC Research Centre, pp. 1-4, 2011.

[15] F. A. Netshiongolwe and J. M. van Coller, "Electrical Stress Monitoring of Distribution Transformers using Bushing Embedded Capacitive Voltage Dividers and Rogowski Coils," Proceeding of International conference on Power System Transients-56, 15th -18th June 2015, pp. 1-8, 2015.

[16] G. M. Hashmi and M. Lehtonen, "Effect of Rogowski coil and covered conductor parameters on the performance of PD measurements in Overhead distribution Networks," 16th PSCC, Glasgow, Scotland, 14th -18th July 2008, pp. 1-7, 2008.

[17] Azriyenni and M. W. Mustafa, "Application of ANFIS for Distance Relay Protection in Transmission Line," International Journal of Electrical and Computer Engineering (IJECE), vol/issue: 5(6), pp. 1311-1318, 2015.

[18] A. S. Paramane, et al., "Rogowski Coil - A Novel Transducer for Current Measurement," 6th International Conference on Power System Protection and Automation, CBIP, New Delhi, India, 27th -28th February 2014, pp. 80-88, 2014.

[19] Datasheet, "MFC-150-Flexible Rogowski Coil," 1DAUMFC15004, Algodue Electronica, Italy.

\section{BIOGRAPHIES OF AUTHORS}
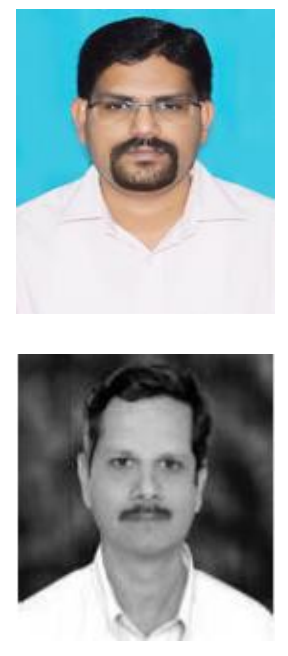

Mr. A.N. Sarwade received his bacholer degree in Electrical Engg from WCE Sangali, Shivaji University, in 1998 and M. Tech (Power System) from College of Engg, Pune University in 2006. Presently he is currently pursuing Ph D from Dr. Babasaheb Ambedkar Techn. University, Lonere and working as faculty member in Sinhgad College of Engg, Pune. His area of research is Power System Protection.

Dr P. K. Katti received his bacholer degree in Electrical Engg from BIET-Davanagere, Mysore University's in 1985, M.E.(Control System) from College of Engg, Pune University in 1991 and $\mathrm{Ph}$. D in Energy system from VNIT, Nagpur in 2007. He has a wide teaching experience, and presently working as Professor in Department of Electrical Engineering, Dr. Babasaheb Ambedkar Tech. University, Lonere, India. His area of research is Renewable Energy. 


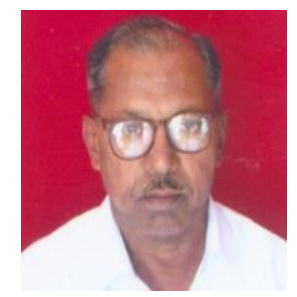

Dr J.G. K. Ghodekar received his Bacholers and Masters degree in Electrical Engg from College of Engg, Pune University in 1964 \& 1975 respectively and Ph. D in Control system from IIT Delhi in 1985. He has a large no. of publications in National and International Journals on his credit. His area of research is Control System. 